\title{
Associations between CD36 gene polymorphisms and susceptibility to coronary artery heart disease
}

\author{
Y. Zhang, Z.Y. Ling, S.B. Deng, H.A. Du, Y.H. Yin, J. Yuan, Q. She and Y.Q. Chen \\ Department of Cardiology, The Second Affiliated Hospital, Chongqing Medical University, Chongqing, China
}

\begin{abstract}
Associations between polymorphisms of the CD36 gene and susceptibility to coronary artery heart disease (CHD) are not clear. We assessed allele frequencies and genotype distributions of CD36 gene polymorphisms in 112 CHD patients and 129 control patients using semi-quantitative polymerase chain reaction (PCR) and restriction fragment length polymorphism (RFLP) analysis. Additionally, we detected CD36 mRNA expression by real-time quantitative PCR, and we quantified plasma levels of oxidized low-density lipoprotein (ox-LDL) using an enzyme-linked immunosorbent assay (ELISA). There were no significant differences between the two groups $(P>0.05)$ in allele frequencies of rs1761667 or in genotype distribution and allele frequencies of rs3173798. The genotype distribution of rs1761667 significantly differed between CHD patients and controls $(P=0.034)$, with a significantly higher frequency of the AG genotype in the CHD group compared to the control group $(P=0.011)$. The plasma levels of ox-LDL in patients with the $A G$ genotype were remarkably higher than those with the $G G$ and AA genotypes $(P=0.010)$. In a randomized sample taken from patients in the two groups, the CD36 mRNA expression of the CHD patients was higher than that of the controls. In CHD patients, the CD36 mRNA expression in AG genotype patients was remarkably higher than in those with an $A A$ genotype $(P=0.005)$. After adjusted logistic regression analysis, the $A G$ genotype of rs 1761667 was associated with an increased risk of $\mathrm{CHD}(\mathrm{OR}=2.337,95 \% \mathrm{Cl}=1.336-4.087, \mathrm{P}=0.003)$. In conclusion, the rs1761667 polymorphism may be closely associated with developing CHD in the Chongqing Han population of China, and an AG genotype may be a genetic susceptibility factor for CHD.
\end{abstract}

Key words: Coronary artery disease; CD36; rs1761667; rs3173798; Single nucleotide polymorphism; ox-LDL

\section{Introduction}

Coronary artery heart disease (CHD) is a major cause of adult cardiovascular morbidity and mortality (1). Atherosclerosis (AS) has been shown to be a critical step in $\mathrm{CHD}$, and lipid metabolism disorder is a key factor in AS (2). Recent studies have found that most CHD patients have a family history of $\mathrm{CHD}$ and that genetic factors play an important role in the incidence of CHD (3). However, the genetic risk factors of $\mathrm{CHD}$ have not been fully determined.

CD36, a member of the B family of scavenger receptors, has been shown to be a high-affinity receptor for oxidized low-density lipoprotein (ox-LDL) and plays a key role in the development of AS (4). It has already been demonstrated that CD36 expression is significantly increased in CHD patients and that this could reflect the severity of coronary artery AS to a certain degree $(5,6)$. In the human CD36 gene, 1372 single nucleotide polymorphisms (SNPs) have been reported to date (7). Associations of some SNPs (e.g., rs5956, rs3173798, and rs3211892) with CHD have been detected, but the conclusions are controversial $(8,9)$. Other SNPs (e.g., rs1761667, rs1527483, rs1049673, and rs3211931) have been shown to be related with type 2 diabetes mellitus (T2DM) or metabolic syndrome (MetS) but do not have direct association with CHD $(10,11)$. Moreover, most of these findings were reported in European populations. Therefore, our study selected two SNPs, rs1761667, located in the $5^{\prime}$ flanking exon $1 \mathrm{~A}$ region (12) and rs3173798, located in the intron 3 region (13), as candidate SNPs to evaluate the genetic and functional effects of CD36 gene polymorphisms on CHD development in the Chongqing Han population of China.

\section{Material and Methods}

\section{Study population}

Patients were enrolled from March 2012 to June 2013 at the Second Affiliated Hospital of Chongqing Medical

Correspondence: Y.Q. Chen, Department of Cardiology, The Second Affiliated Hospital, Chongqing Medical University, No. 76 , Lingjiang Road, Yuzhong District, Chongqing 400010, China. Fax: +86-023-6371-0026. E-mail: chenyunqing.88@163.com 


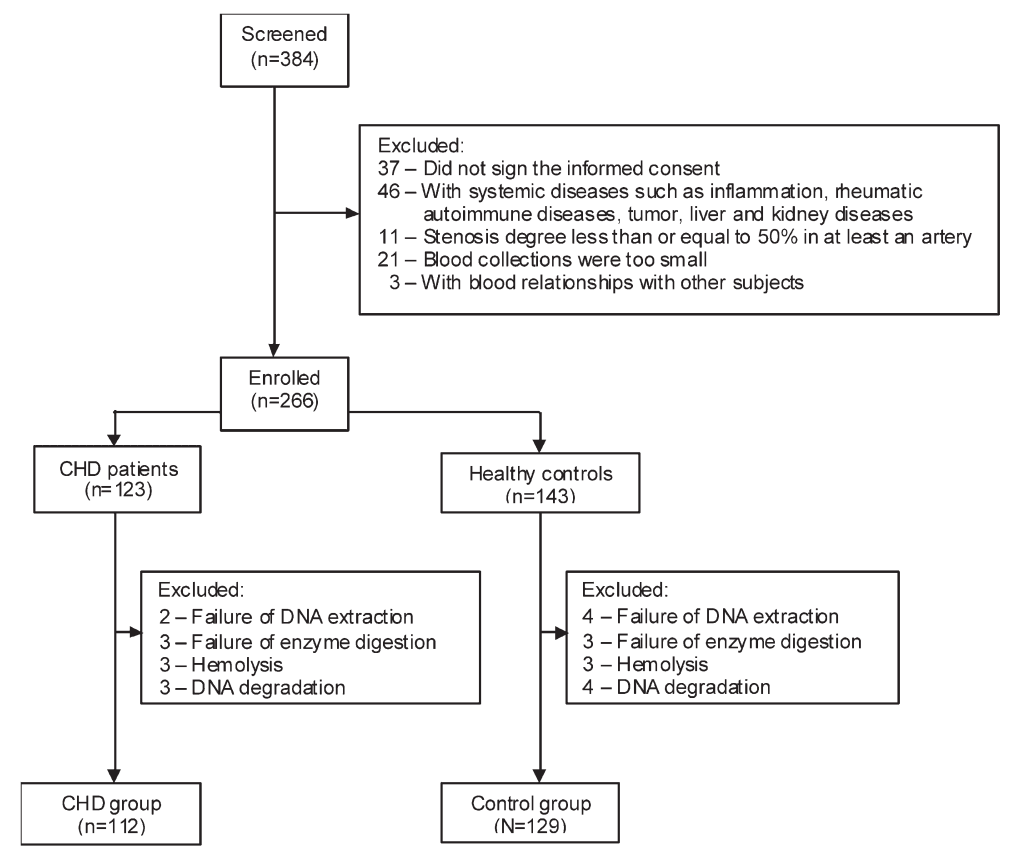

Figure 1. Flow chart of the trial.

University. The enrollment criteria for patients in the $\mathrm{CHD}$ group included: a) older than 18 years of age, b) a diagnosis of CHD according to the World Health Organization (WHO) CHD diagnostic criteria set in 1979, and c) a stenosis degree greater than or equal to $50 \%$ in at least one artery determined by angiography. Healthy outpatients were included in the control group. Extreme care was taken to exclude CHD patients through relevant examinations. The case exclusion criteria included patients with: a) systemic diseases such as inflammation, rheumatic autoimmune diseases, tumor, liver and kidney diseases and b) any kinship association with any other subject. This study was approved by the Medical Ethics Committee of the Second Affiliated Hospital of Chongqing Medical University. Written informed consent was given by every patient or her/his legally authorized representative prior to study participation.

\section{Sample size}

Sample size was calculated by Quanto 1.2.4 (Copyright ${ }^{\odot}$ 2000-2009, University of Southern California), with a choice of gene-only model and a population prevalence ratio of $6.49 \%$ (14). According to the National Center for Biotechnology Information (NCBI), allele frequencies of rs1761667 and rs3173798 were 0.572 and 0.811 , respectively. Using $80 \%$ power, a type I error rate of 0.05 and a two-sided statistical test, the required sample size per group was calculated to be 102 patients. Taking into consideration the success rate of genotype identification and the analysis of interaction, we initially enrolled a total of 266 patients (123 in the CHD group and 143 in the control group, Figure 1).
Sample preparation, DNA isolation, and genotyping

First, $2 \mathrm{~mL}$ peripheral venous blood was collected from each subject using EDTA-anticoagulant tubes. Then, genomic DNA was extracted according to a standard protocol using a TIANamp blood DNA kit (TIANGEN, China), and was genotyped by polymerase chain reaction-restriction fragment length polymorphism (PCR-RFLP) for rs 1761667 and rs3173798. The primers (TAKARA, Japan), amplification parameters, and restriction enzymes for each round of PCR are shown in Table 1. The target DNA sequence of rs3173798 was amplified by mismatched and nested PCR. The digestion products were visualized on a $4 \%$ agarose gel and stained with GoldView ${ }^{\mathrm{TM}}$ (SBS Genetech, China).

Direct sequencing was also performed by the Shanghai Invitrogen Co., Ltd. (China) for randomly selected subjects to validate the methods used in this study.

\section{Real-time quantitative PCR}

Total RNA was extracted from peripheral blood samples of patients using the TRIzol Reagent (TIANGEN, China), chloroform, and isopropanol. cDNA was then synthesized using a reverse transcription kit (TAKARA). Real-time PCR was performed to compare CD36 mRNA expression between the two groups and was determined using the SYBR ${ }^{\circledR}$ Premix Ex Taq ${ }^{\mathrm{TM}}$ ॥ (Perfect Real Time, TAKARA) and normalized to $\beta$-actin mRNA levels. The relative expression levels were calculated using the $2^{-\Delta \Delta C t}$ method (15). The sense and antisense primers used in this experiment are shown in Table 2.

\section{Enzyme-linked immunosorbent assay (ELISA)}

Plasma ox-LDL concentrations were measured by 
Table 1. Primers, amplification parameters and restriction enzymes of polymerase chain reaction.

\begin{tabular}{|c|c|c|}
\hline Primers & Amplification parameters & $\begin{array}{l}\text { Length of PCR products/ } \\
\text { Restriction enzymes }\end{array}$ \\
\hline rs3173798 & & $121 \mathrm{bp}$ \\
\hline \multicolumn{3}{|l|}{ First round } \\
\hline Sense: 5'-AATGAGGTACTTGGGCTTGGT-3' & $\begin{array}{l}95^{\circ} \mathrm{C} 2 \mathrm{~min} ; 94^{\circ} \mathrm{C} 30 \mathrm{~s}, 60^{\circ} \mathrm{C} 1 \mathrm{~min}, \\
72^{\circ} \mathrm{C} 1 \mathrm{~min}, 35 \text { cycles }\end{array}$ & Ncol \\
\hline Anti-sense: 5'-CAGAAATACATGGTCAAGGTAAGAG-3' & $72^{\circ} \mathrm{C} 10 \mathrm{~min}, 4^{\circ} \mathrm{C}$ storage & \\
\hline \multicolumn{3}{|l|}{ Second round } \\
\hline Sense: 5'-TTGGGCTTGGTCCTTTTATTCT-3' & $\begin{array}{l}94^{\circ} \mathrm{C} 3 \mathrm{~min} ; 94^{\circ} \mathrm{C} 1 \mathrm{~min}, 62^{\circ} \mathrm{C} 1 \mathrm{~min}, \\
72^{\circ} \mathrm{C} 1 \mathrm{~min}, 35 \text { cycles }\end{array}$ & \\
\hline Anti-sense: 5'-TCGAGGACAACTTGCCATGG-3' & $72^{\circ} \mathrm{C} 5 \mathrm{~min}, 4^{\circ} \mathrm{C}$ storage & \\
\hline rs1761667 & & $595 \mathrm{bp}$ \\
\hline Sense: 5'-TCGTATCCTGTCACTCCTCCAA-3' & $\begin{array}{l}95^{\circ} \mathrm{C} 2 \mathrm{~min} ; 94^{\circ} \mathrm{C} 30 \mathrm{~s}, 60^{\circ} \mathrm{C} 1 \mathrm{~min}, \\
72^{\circ} \mathrm{C} 1 \mathrm{~min}, 35 \mathrm{cycles}\end{array}$ & Haell \\
\hline Anti-sense: 5'-GCTATCATGGAAACCAAGAAAGAC-3' & $72^{\circ} \mathrm{C} 10 \mathrm{~min}, 4^{\circ} \mathrm{C}$ storage & \\
\hline
\end{tabular}

PCR: polymerase chain reaction. * The mismatched primer: the base $\mathrm{T}$ was mismatched to $\mathrm{C}$, and then a restriction site of Ncol $(C \uparrow C A T G G)$ can be introduced.

ELISA. Whole blood was centrifuged at $750 \mathrm{~g}$ to separate plasma from blood cells. Then, the subsequent steps in the protocol were conducted according to the manufacturer's recommendations (Shanghai Hushang Co., Ltd., China). Finally, the absorbance was immediately assayed at $450 \mathrm{~nm}$ using a micro-plate reader (Thermo Fisher 1510, USA).

\section{Statistical analysis}

Data are reported as means $\pm S D$, as counts or as percentages. A $\chi^{2}$-test or the Student $t$-test was performed to compare the genotypes and means between the two groups. Statistical analyses for multiple group data measurements were performed using one-way analysis of variance (ANOVA), and a subsequent least significant difference (LSD) test was used to compare any two means when there were significant differences among multiple groups. $\mathrm{P}<0.05$ was considered to be statistically significant. Hardy-Weinberg equilibrium was tested using a $\chi^{2}$ test to judge the reliability of the gene frequency. Logistic regression analysis was performed to screen for CHD risk factors, to predict the occurrence of $\mathrm{CHD}$, and to reveal the association of rs 1761667 polymorphism with $\mathrm{CHD}$. Odds ratios (ORs) with $95 \%$ confidence intervals $(\mathrm{Cls})$ were used to estimate the significance of differences in relative risk. PASW Statistics 18.0 (WinWrap ${ }^{\circledR}$ Basic, USA) was used for all the analyses.

\section{Results}

\section{Baseline clinical characteristics}

The CHD group included 112 patients (69 males), with an average age of $64.04 \pm 10.27$ years, while the control group included 129 patients (55 males), with an average age of $61.68 \pm 14.80$ years. The detailed clinical characteristics are shown in Table 3.

\section{Genotypes and allele frequencies}

RFLP analysis confirmed that there were three genotypes (GG, AG, and AA) for rs1761667 (Figure 2A) and three genotypes (TT, CT, and CC) for rs3173798 (Figure 3A) in the chipping fragments. The distribution of rs 1761667 genotypes between the two groups was significantly different $(P=0.034)$, with the frequency of the AG genotype being significantly higher in the CHD group than in the control group $(P=0.011$, Figure $2 B)$. There were no significant differences between the two groups in the allele frequencies of rs1761667 or in the genotype distribution and allele

Table 2. Primers and amplification parameters of real time polymerase chain reaction.

\begin{tabular}{|c|c|c|}
\hline Target gene/primer & Base sequence & Amplification parameters \\
\hline \multicolumn{3}{|l|}{$C D 36$} \\
\hline Sense & 5'-CAGTTCTCAATCTGGCTGTGGC-3' & $95^{\circ} \mathrm{C} 30 \mathrm{~s} ; 95^{\circ} \mathrm{C} 5 \mathrm{~s}, 58^{\circ} \mathrm{C} 30 \mathrm{~s}$, plate read \\
\hline Anti-sense & 5'-AACAGGGTACGGAACCAAACTCA-3' & $72^{\circ} \mathrm{C} 1 \mathrm{~min}, 39$ cycles \\
\hline \multicolumn{3}{|l|}{$\beta$-actin } \\
\hline Sense & 5'-CCACGAAACTACCTTCAACTCC-3' & Melt curve $65^{\circ} \mathrm{C}$ to $95^{\circ} \mathrm{C}$ \\
\hline Anti-sense & 5'-GTGATCTCCTTCTGCATCCTGT-3' & Increment $0.5^{\circ} \mathrm{C}$ for $5 \mathrm{~s}$, plate read \\
\hline
\end{tabular}


Table 3. Baseline clinical and examination data of the two groups.

\begin{tabular}{lccc}
\hline & CHD group $(\mathrm{n}=112)$ & Control group $(\mathrm{n}=129)$ & $\mathrm{P}$ \\
\hline Age (years) & $64.04 \pm 10.27$ & $61.68 \pm 14.80$ & 0.15 \\
Male & $69(61.61)$ & $55(42.64)$ & $0.003^{*}$ \\
Weight $(\mathrm{kg})$ & $63.67 \pm 9.08$ & $61.90 \pm 7.81$ & 0.11 \\
Height $(\mathrm{m})$ & $1.64 \pm 0.08$ & $1.62 \pm 0.09$ & 0.10 \\
BMl $\left(\mathrm{kg} / \mathrm{m}^{2}\right)$ & $23.78 \pm 2.85$ & $23.62 \pm 1.96$ & 0.62 \\
Hypertension & $74(66.07)$ & $71(55.04)$ & 0.08 \\
Dyslipidemia & $67(59.82)$ & $64(49.61)$ & 0.11 \\
T2DM & $26(23.21)$ & $20(15.50)$ & 0.13 \\
Smoking history & $41(36.61)$ & $23(17.83)$ & $0.001^{*}$ \\
Family history of CHD & $15(13.39)$ & $6(4.65)$ & $0.02^{*}$ \\
Previous Ml & $5(4.46)$ & 0 & 0.05 \\
Previous GABG & 0 & 0 & - \\
Previous PCl & $9(8.04)$ & 0 & $0.003^{*}$ \\
EF (\%) & $69.69 \pm 7.76$ & $69.43 \pm 10.43$ & 0.82 \\
TG (mM) & $1.72 \pm 0.78$ & $1.77 \pm 1.26$ & 0.79 \\
TC (mM) & $4.75 \pm 1.05$ & $4.58 \pm 1.19$ & 0.23 \\
HDL (mM) & $1.21 \pm 0.41$ & $1.21 \pm 0.34$ & 0.95 \\
LDL (mM) & $2.95 \pm 0.93$ & $2.72 \pm 0.80$ & 0.05 \\
\hline
\end{tabular}

Data are reported as means $\pm S D$ or number with percent in parentheses. CHD: coronary artery heart disease; BMI: body mass index T2DM: type 2 diabetes mellitus; MI: myocardial infarction; GABG: coronary artery bypass grafting; PCl: percutaneous coronary intervention; EF: ejection fraction; TG: triglycerides; TC: total cholesterol; HDL: high-density lipoprotein; LDL: low-density lipoprotein. * There were significant differences in males, smoking history, patients with family history of CHD and with previous $\mathrm{PCl}$ between the two groups. The $\chi^{2} / t$-test was used for statistical analyses.

frequencies of rs3173798 (all $\mathrm{P}>0.05$; Figures 2C, 3B and C). The genotype distribution of rs1761667 and rs3173798 conformed well to the Hardy-Weinberg expectation in both groups (all $\mathrm{P}>0.05$ )

The results of direct sequencing were consistent with identifications made by agarose gel electrophoresis.

\section{CD36 mRNA expression in patient subgroups}

We genotyped 42 cases for the 3 genotypes of rs1761667 occurring randomly in CD36 and then detected their CD36 mRNA expression by real-time PCR. The expression of CD36 at the mRNA level in the CHD group was significantly higher than that in the control group $(P<0.001)$, with significant differences in the $C H D$ patients with an AG genotype of rs1761667 compared with those with an AA genotype $(P=0.005$, Figure 4).

\section{Plasma ox-LDL levels}

ELISA analysis indicated that the plasma levels $(\mathrm{pg} / \mathrm{mL})$ of ox-LDL in the CHD group were much higher than that in the control group $(P=0.037)$. Furthermore, the plasma ox-LDL levels in CHD patients were significantly different in patients with the three different genotypes $(P=0.010$, Figure 5).

\section{Screening for risk factors of CHD}

We screened the risk factors of CHD and predicted its occurrence with logistic regression analysis. Genotypes of rs1761667 and rs3173798 were considered, as well as traditional risk factors of $\mathrm{CHD}$ such as age, sex, body mass index (BMI), hypertension, dyslipidemia, T2DM, smoking history and family history of CHD, triglycerides (TG), tota cholesterol (TC), high-density lipoprotein (HDL), and LDL. The results showed that age, current smoking, family history of CHD, LDL and the AG genotype of rs 1761667 factored into the final equation $(\mathrm{P}<0.05$, Table 4$)$. The predictive equation was established according to the parameters in Table 4: Logit $(P)=\operatorname{Ln}(P /[1-P])=0.849(A G$ genotype) +0.027 (age) +0.365 (LDL) +1.314 (current smoking) +1.327 (family history of $\mathrm{CHD}$ ) -3.711 . $\mathrm{P} \geq 0.5$ indicates occurrence of $\mathrm{CHD}$, and $\mathrm{P}<0.5$ indicates no occurrence of CHD. The accuracy, sensitivity, specificity and Youden index of the logistic regression model were 65.98, 54.05, 76.15, and $0.302 \%$, respectively.

\section{Effect of rs1761667 polymorphism on CHD}

Table 5 shows that the AG genotype could increase the risk of $\mathrm{CHD}$ in both unadjusted and adjusted logistic regression models (unadjusted $\mathrm{OR}=1.947,95 \% \mathrm{Cl}=$ 1.163-3.259, $\mathrm{P}=0.011$; adjusted $\mathrm{OR}=2.337,95 \% \mathrm{Cl}=$ 1.336-4.087, $P=0.003)$

\section{Associations of rs1761667 genotypes with clinical indexes in the CHD group}

No differences were observed in TG, TC, HDL, LDL, or $\mathrm{BMI}$ of CHD patients with different genotypes of rs 1761667 (all $\mathrm{P}>0.05$, Table 6). 

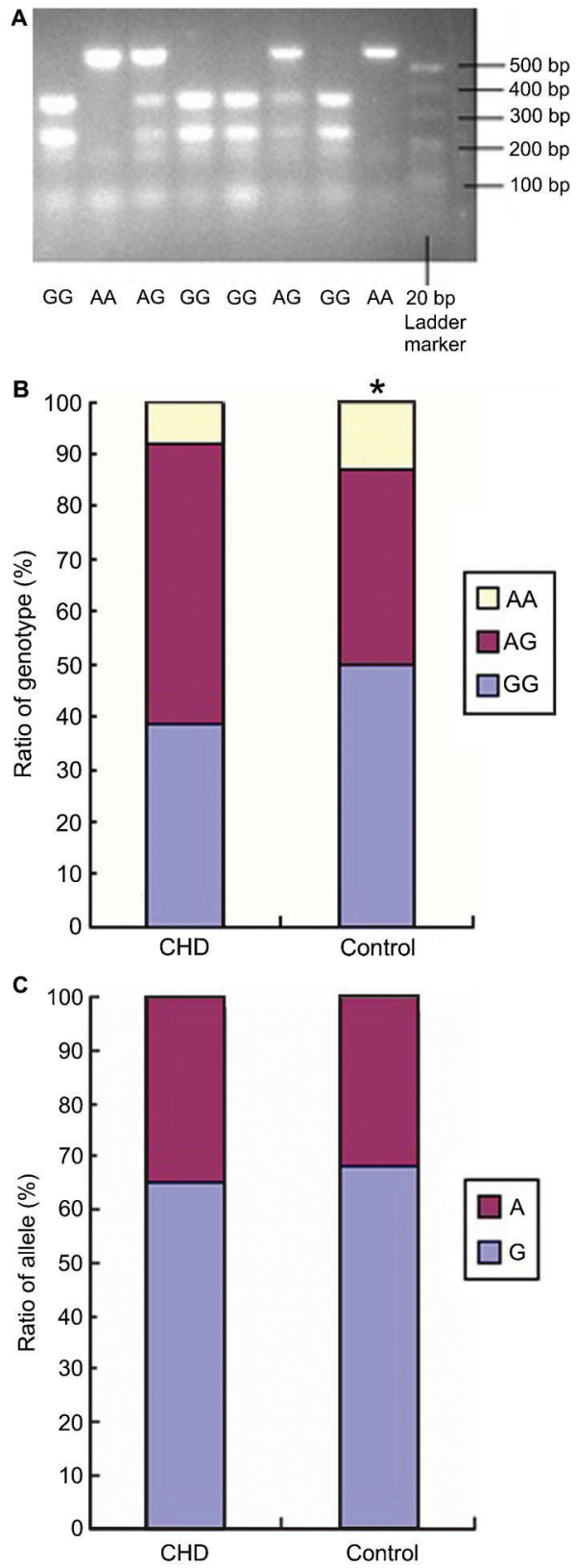

Figure 2. Distribution of genotypes and alleles of rs1761667 between coronary artery heart disease (CHD) patients and healthy controls. $A$, There are three genotypes of rs1761667 in the chipping fragments displayed by RFLP analysis: AA (595 bp), GG (362+233 bp) and AG $(595+362+233 \mathrm{bp})$. $B$, The frequencies of three kinds of genotypes (GG, AG, AA) of rs1761667 in the CHD group and control group were $38.39,53.57,8.04 \%$, and $49.61,37.21,13.18 \%$, respectively. The distribution of genotypes in the CHD group and control group had a significant difference $\left({ }^{*} \mathrm{P}=0.034\right)$, with the frequency of $A G$ genotype significantly higher in the CHD group than in the control group $(P=0.011)$. $C$, The frequencies of $\mathrm{G} / \mathrm{A}$ alleles of $\mathrm{rs} 1761667$ in the $\mathrm{CHD}$ group and control group were $65.18,34.82$, and $68.22,31.78 \%$, respectively. No significant difference in the distributions of $\mathrm{G} / \mathrm{A}$ allele frequencies was observed between the two groups $(P=0.480)$. The $\chi^{2}$ test was used for statistical analyses.
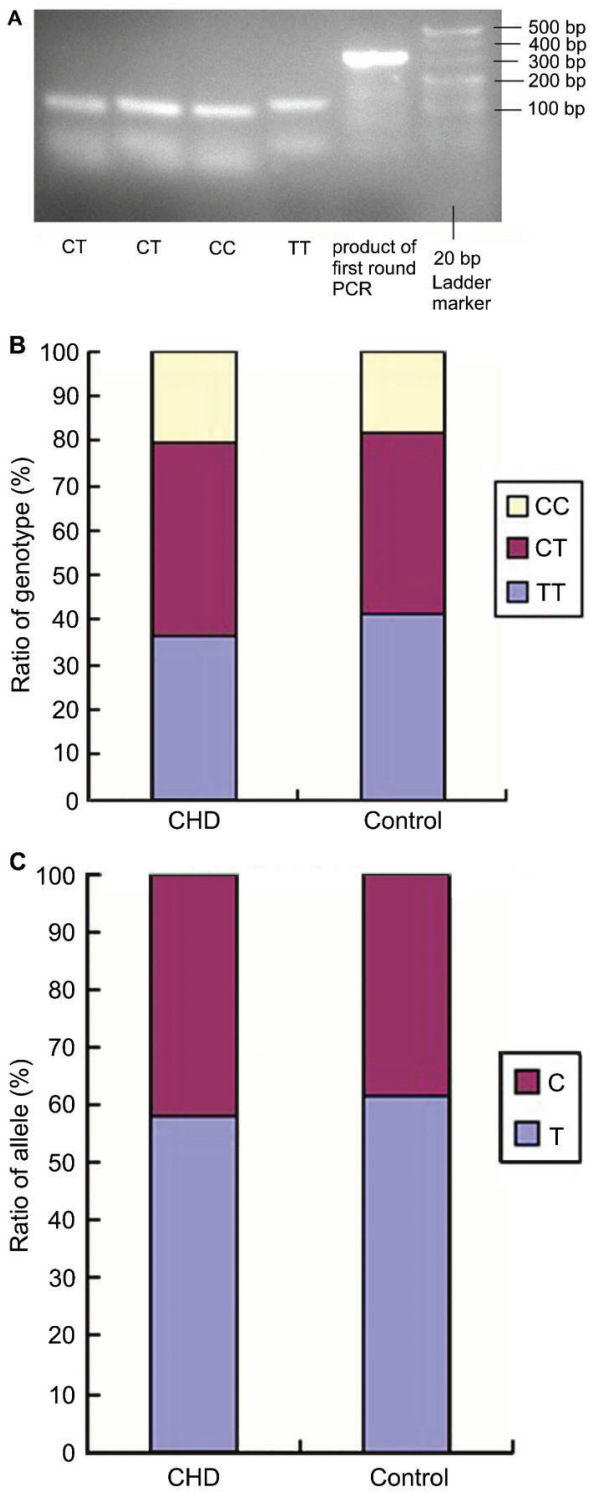

Figure 3. Distribution of genotypes and alleles of rs3173798 between coronary artery heart disease (CHD) patients and healthy controls. $A$, There are three genotypes of rs3173798 in the chipping fragments displayed by RFLP analysis: TT (121 bp), CC (102+19 bp) and CT $(121+102+19 \mathrm{bp})$ in theory, but, the molecule of $19 \mathrm{bp}$ was so small that the band of electrophoresis was too weak to observe, and the molecule of 121 and $102 \mathrm{bp}$ were too close that the bands of electrophoresis were not easily to distinguished. Thus, CC genotype had only one band of $102 \mathrm{bp}$, and CT genotype had a thick and bright band of the combination of 121 and $102 \mathrm{bp}$. B. Frequencies of the three genotypes (TT, CT, CC) of rs3173798 in the CHD group and control group were $36.61,42.86,20.53 \%$, and $41.54,40.00,18.46 \%$, respectively. There was no significant difference in distribution of genotypes between the two groups $(P=0.732)$. $C$, Frequencies of $C /$ $\mathrm{T}$ alleles of rs3173798 in the CHD group and control group were $58.04,41.96$, and $61.54,38.46 \%$, respectively. No significant difference in the distributions of $\mathrm{C} / \mathrm{T}$ allele frequencies was observed between the two groups $(P=0.433)$. The $\chi^{2}$ test was used for statistical analyses. 

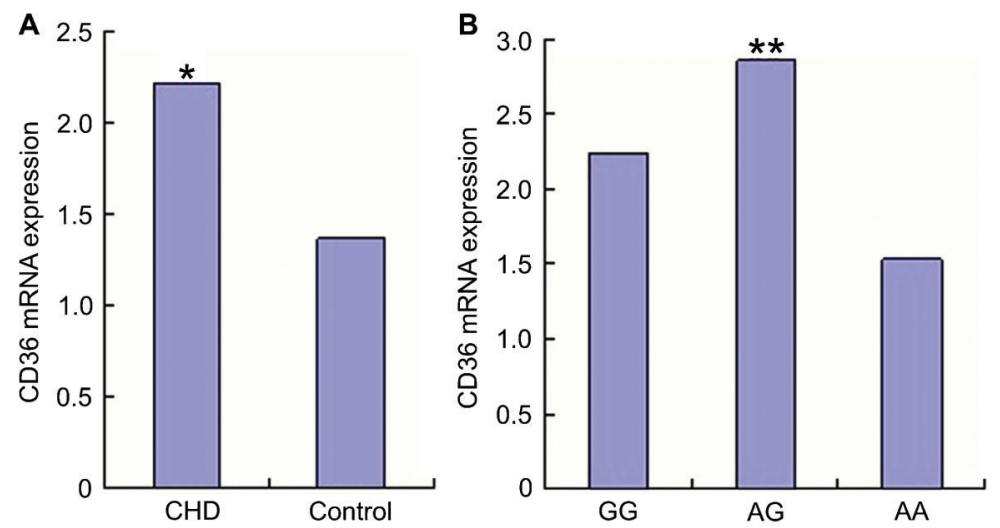

Figure 4. CD36 mRNA expression of coronary artery heart disease (CHD) patients and healthy controls. $A$, The expression of CD36 mRNA in CHD patients $(2.21 \pm 1.55)$ was significantly higher than that of healthy controls $(1.36 \pm 1.01$; $\mathrm{P}<0.001)$. $B$, There were significant differences in the CD36 mRNA expression in CHD patients with different genotypes of rs 1761667 $\left({ }^{* *} \mathrm{P}=0.018\right)$, and the CD36 mRNA expression in $\mathrm{CHD}$ patients with $\mathrm{AG}$ genotype $(2.86 \pm 1.70)$ were remarkably higher than those with $A A$ genotype (1.53 $\pm 0.78 ; P=0.005)$. No significant differences were observed in CD36 mRNA expression of $\mathrm{CHD}$ patients with $\mathrm{GG}$ $(2.24 \pm 1.72)$ and $A G$ or $A A$ genotype $(\mathrm{P}=0.173, \mathrm{P}=0.125$, respectively). The $t$-test was used for statistical analyses.

\section{Discussion}

\section{Main findings}

We evaluated the associations between polymorphisms of the rs1761667/rs3173798 SNPs in the CD36 gene and the susceptibility to CHD in $112 \mathrm{CHD}$ patients and 129 healthy controls in the Chongqing Han population of China. We found significant differences in the genotype distribution of rs 1761667 between the CHD and control groups, with a significantly higher frequency of the $A G$ genotype in the CHD group compared to the control group. The plasma levels of ox-LDL in patients with CHD were higher than those of controls and were related to the genotypes of rs1761667. In a randomized sample from the two groups, CD36 mRNA expression was higher in $\mathrm{CHD}$ patients than in controls and was related to specific rs1761667 genotypes.

These findings indicated that rs1761667 polymorphism may be closely associated with the risk of developing $\mathrm{CHD}$ in the Chongqing Han population of China, and that the AG genotype may be a genetic susceptibility factor for $\mathrm{CHD}$. To our knowledge, this is the first time that an association has been reported between rs 1761667 polymorphism in the CD36 gene and CHD, particularly in relation to the AG genotype in rs1761667. This result may provide evidence for the role of rs1761667 polymorphism in $\mathrm{CHD}$ development.

\section{Association between CD36 and diseases}

CD36 has been shown to have functions in mediating the uptake of ox-LDL and acting as a high affinity receptor for oxLDL in foam cell formation. Researchers hypothesize that it plays a role in the development of CHD. They have found that CD36 expression in monocytes is increased in patients with $\mathrm{CHD}$ and that this could reflect the severity of coronary artery AS to a certain extent $(5,6)$. Moreover, CD36 mRNA expression has been shown to increase significantly in patients with $\mathrm{CHD}$, and its expression in circulating monocytes may be a marker for CHD $(16,17)$. Therefore, we randomly genotyped $42 \mathrm{CHD}$ patients carrying three genotypes of the rs 1761667 allele and then detected their CD36 mRNA expression. The mRNA expression level of CD36 in the CHD group was significantly higher than that in the control group $(P<0.001)$. Our results are similar to those
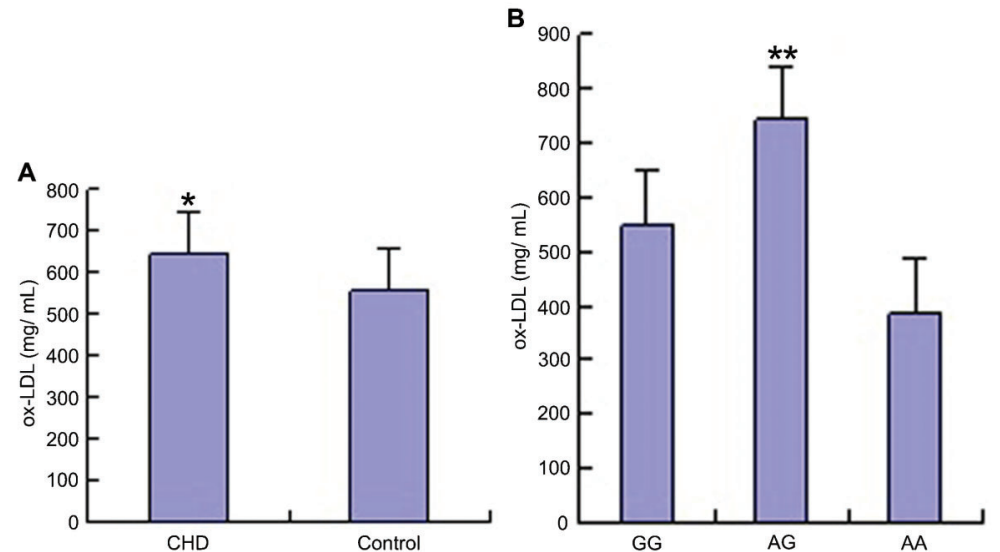

Figure 5. Plasma level of ox-LDL between coronary artery heart disease (CHD) patients and healthy controls. A. The plasma level of oxLDL in CHD patients $(646.24 \pm 369.99 \mu \mathrm{g} / \mathrm{L})$ was significantly higher than that of healthy controls $(555.91 \pm 283.68 \mu \mathrm{g} / \mathrm{L})$, with ${ }^{*} P=0.037$. $B$, There were significant differences in the plasma levels of ox-LDL in CHD patients with different genotypes of rs1761667 ( $\left.{ }^{* *} \mathrm{P}=0.010\right)$; and the plasma levels of ox-LDL in CHD patients with $A G$ genotype $(741.38 \pm 418.39 \mu \mathrm{g} / \mathrm{L})$ were significantly higher than those with $G G$ and $A A$ genotypes $(551.01 \pm 271.41 \mu \mathrm{g} / \mathrm{L}, P=0.009$; $386.35 \pm 201.52 \mu \mathrm{g} / \mathrm{L}, \quad P=0.034$, respectively). No significant differences were observed in plasma levels of $\mathrm{CHD}$ patients with $\mathrm{GG}$ and $\mathrm{AA}$ genotypes $(P=0.523)$. The $t$-test was used for statistical analyses. 
Table 4. Results of logistic regression analysis for screening risk factors of coronary artery heart disease (CHD) and predicting occurrences of CHD.

\begin{tabular}{lcccccrrr}
\hline Risk factors & B & S.E. & Wald & df & OR & $95 \% \mathrm{Cl}$ & $\mathrm{P}$ \\
\hline AG genotype & 0.849 & 0.285 & 8.853 & 1 & 2.337 & $1.336-4.087$ & 0.003 \\
Age (years) & 0.027 & 0.012 & 5.069 & 1 & 1.027 & $1.003-1.051$ & 0.024 \\
LDL (mM) & 0.365 & 0.164 & 4.935 & 1 & 1.44 & $1.044-1.988$ & 0.026 \\
Smoking history & 1.314 & 0.338 & 15.107 & 1 & 3.722 & $1.918-7.221$ & $<0.001$ \\
Family history of CHD & 1.327 & 0.534 & 6.176 & 1 & 3.769 & $1.324-10.732$ & 0.013 \\
Constant & -3.711 & 0.981 & 14.32 & 1 & 0.024 & & $<0.001$ \\
\hline
\end{tabular}

Given values: non- $A G=0, A G=1 ; A g e, L D L=$ continuous variables; non-smoking history $=0$; smoking history =1; non-family history of $\mathrm{CHD}=0$; family history of $\mathrm{CHD}=1$. LDL: low-density lipoprotein.

reported in previous studies, but in contrast to those reports, we compared the CD36 mRNA expression levels of CHD patients carrying different genotypes and found that the expression was significantly higher in CHD patients with the $A G$ genotype than in those with the AA genotype $(P=0.005)$.

\section{Associations between rs1761667 polymorphism in the CD36 gene and diseases}

Although rs1761667 polymorphism affects lipid metabolism and oral fat perception and the genotype AG was found to be more prevalent among MetS and T2DM patients $(10,18)$, the association of rs1761667 polymorphism with $\mathrm{CHD}$ remains to be clarified. In accordance with the previously mentioned studies, we found rs1761667 polymorphism in the CHD group. Contrary to those studies, our subjects were actual patients with $\mathrm{CHD}$. We found that the genotype distributions of rs1761667 in the $\mathrm{CHD}$ and control groups were significantly different $(P=0.034)$, with the frequency of the $A G$ genotype being significantly higher in the CHD group $(P=0.011)$. No significant difference was observed in the allele frequencies of $G / A$ between the two groups $(P=0.480)$. After adjustments for age, sex, BMI, hypertension, dyslipidemia, T2DM, smoking history, family history of CHD, TG, TC, $\mathrm{HDL}$, and LDL in logistic regression, the results still indicated that the AG genotype of rs1761667 correlated with an increased risk of CHD (OR $=2.337,95 \%$ $\mathrm{Cl}=1.336-4.087, \mathrm{P}=0.003)$. Logistic regression analysis showed that the AG genotype of rs1761667 was an independent risk factor for CHD. Furthermore, we found that rs 1761667 polymorphism was closely related to CD36 mRNA expression and ox-LDL plasma levels. These results indicated that polymorphism of rs1761667 may be associated with the risk of CHD in the Chongqing Han population of China and that the AG genotype may be a genetic susceptibility factor for patients with CHD. To the best of our knowledge, this is the first study to report on an association between rs1761667 polymorphism and CHD.

\section{Associations between rs3173798 polymorphism in the $C D 36$ gene and diseases}

Recent studies on the polymorphisms of the CD36 gene indicate that rs3173798 polymorphism may impact MetS pathophysiology and HDL metabolism and may lead to higher prevalence rates of obesity and diabetes, as well as increased high-sensitivity C-reactive protein level, all of which are cardiovascular risk factors $(19,20)$. However, other studies did not find evidence that rs3173798 polymorphism was associated with radiological markers of AS progression in Caucasian patients diagnosed with CHD at a young age. Additionally, rs3173798 did not seem to be involved in the risk of early onset CHD in Caucasian populations $(8,9)$. Associations of rs3173798 polymorphism with $\mathrm{CHD}$ seem to be controversial. Furthermore, most of the studies assessed European populations. Similar to the above-mentioned studies $(8,9)$, we observed an rs3173798 polymorphism in the CHD group, but there was no significant difference in the distribution of genotypes and $\mathrm{T} / \mathrm{C}$

Table 5. Effect of rs1761667 polymorphism on coronary artery heart disease.

\begin{tabular}{lcccc}
\hline Genotypes & CHD $(n)$ & Control $(n)$ & Unadjusted & Adjusted \\
\cline { 3 - 5 } & & & OR $(95 \% C l) P$ & OR $(95 \% C l) P$ \\
\hline GG & 43 & 64 & $0.633(0.379-1.058) 0.081$ & $0.573(0.325-1.012) 0.055$ \\
AG & 60 & 48 & $1.947(1.163-3.259) 0.011$ & \\
AA & 9 & 17 & $0.576(0.246-1.348) 0.203$ & \\
\hline
\end{tabular}

Given values: non- $G G=0, G G=1$; non- $A G=0, A G=1$; non- $A A=0, A A=1$. *Factors adjusted in logistic regression analysis were age, sex, body mass index, hypertension, dyslipidemia, type 2 diabetes mellitus, smoking history, family history of coronary artery heart disease (CHD), triglycerides, total cholesterol, high-density lipoprotein, and low-density lipoprotein. 
Table 6. Association of rs 1761667 polymorphism with clinic indexes in the coronary artery heart disease group.

\begin{tabular}{lrrrr}
\hline & \multicolumn{1}{c}{ GG } & \multicolumn{1}{c}{ AG } & AA & P (t-test) \\
\hline TG $(\mathrm{mM})$ & $1.75 \pm 0.62$ & $1.65 \pm 0.86$ & $2.10 \pm 0.84$ & 0.256 \\
TC $(\mathrm{mM})$ & $4.96 \pm 1.13$ & $4.60 \pm 1.02$ & $4.82 \pm 0.67$ & 0.223 \\
HDL $(\mathrm{mM})$ & $1.23 \pm 0.33$ & $1.20 \pm 0.46$ & $1.23 \pm 0.42$ & 0.939 \\
LDL $(\mathrm{mM})$ & $3.07 \pm 1.04$ & $2.88 \pm 0.87$ & $2.81 \pm 0.72$ & 0.516 \\
BMI & $23.19 \pm 3.02$ & $24.17 \pm 2.11$ & $22.44 \pm 2.71$ & 0.056 \\
\hline
\end{tabular}

TG: triglyceride; TC: total cholesterol; HDL: high-density lipoprotein; LDL: low-density lipoprotein; BMI: body mass index.

allele frequencies between the two groups in the Chongqing Han population (all $\mathrm{P}>0.05$ ). We preliminarily deduced that rs3173798 polymorphism had no direct correlation with CHD.

Relationship of rs1761667 polymorphism in the CD36 gene with CD36 mRNA expression

Similar to previous publications $(16,17)$, we found that CD36 mRNA expression was significantly higher in the CHD group than in the control group in a randomized sample taken from the two groups $(P<0.001)$.

Furthermore, we compared CD36 mRNA expression among a random total of $21 \mathrm{CHD}$ patients carrying different genotypes of rs1761667 and found that the CD36 mRNA expression in the CHD patients with an AG genotype was remarkably higher than in those with the $A A$ genotype $(P=0.005)$. This result indicated that rs1761667 polymorphism seems to be involved in CHD pathogenesis.

\section{Relationship of rs1761667 polymorphism in the CD36 gene with ox-LDL}

It is well known that the combination of ox-LDL with CD36 can induce foam cell formation and CHD development. A previous study indicated that ox-LDL concentrations were higher in $\mathrm{CHD}$ individuals than in non-CHD individuals (21), and our findings were similar. Another study (22) suggested a significant interaction between CD36 gene polymorphisms and ox-LDL metabolism in the etiology of colorectal cancer. However, there have been few reports on the association of plasma ox-LDL levels with CD36 polymorphisms in CHD patients. We found that $\mathrm{CHD}$ patients with an AG genotype had higher plasma ox-LDL levels than those with $G G$ or $A A$ genotypes $(P=0.010)$. This demonstrates that plasma ox-LDL level and rs1761667

\section{References}

1. Pu J, Mintz GS, Biro S, Lee JB, Sum ST, Madden SP, et al. Insights into echo-attenuated plaques, echolucent plaques, and plaques with spotty calcification: novel findings from comparisons among intravascular ultrasound, near-infrared spectroscopy, and pathological histology in 2294 human coronary artery segments. J Am Coll Cardiol 2014; 63: 2220-2233, doi: 10.1016/j.jacc.2014.02.576. polymorphism have a close relationship. We conclude that the AG genotype of the rs1761667 polymorphism in the CD36 gene may be involved in CHD pathogenesis.

\section{Limitations}

Although CHD is a common disease and occurs frequently, the percentage of patients who undergo angiography is relatively small. Although angiography is recommended for symptomatic patients, less than 50 percent of patients actually complete one. This may be due to the poor economy and conservative approach to healthcare in the southwestern region of China. The subjects of our study were CHD patients with angiography-confirmed stenosis of $50 \%$ or more in at least one artery. This inclusion criterion tended to reduce the size of the enrollment-eligible population. In addition, as our study was only performed in the Chongqing Han region of China, it is not entirely clear whether this association may also exist in other populations. Furthermore, although our results suggested that rs1761667 in the $C D 36$ gene was associated with the development of $\mathrm{CHD}$, it is still unknown whether and how the SNP influences $\mathrm{CHD}$. Therefore, it is necessary to perform studies with a larger sample size and to include data from other racial and regional populations. More functional and linkage studies are also required to investigate the exact role that CD36 gene polymorphisms play in CHD.

\section{Acknowledgments}

Research partially supported by grants from the Natural Science Foundation of China (\#81070140) and the project of the Chongqing Health Administration (\#2008-2-45).
2. Pu J, Mintz GS, Brilakis ES, Banerjee S, Abdel-Karim AR, Maini $B$, et al. In vivo characterization of coronary plaques: novel findings from comparing greyscale and virtual histology intravascular ultrasound and near-infrared spectroscopy. Eur Heart J 2012; 33: 372-383, doi: 10.1093/eurheartj/ehr387.

3. Kessler T, Erdmann J, Schunkert H. Genetics of coronary artery disease and myocardial infarction - 2013. Curr Cardiol 
Rep 2013; 15: 368, doi: 10.1007/s11886-013-0368-0.

4. Collot-Teixeira S, Martin J, McDermott-Roe C, Poston R, McGregor JL. CD36 and macrophages in atherosclerosis. Cardiovasc Res 2007; 75: 468-477, doi: 10.1016/j.cardiores. 2007.03.010.

5. Zhou Q, Wang ML, He SH, et al. Changes of the CD36 expression in peripheral blood monocytes in coronary heart disease, hypercholesterolemia and diabetes mellitus. Int $J$ Lab Med 2007; 28: 769-771.

6. Lei J, Luo ZF, Wei J, et al. Correlation between CD36 level of monocyte and the severity of coronary artery atherosclerosis. Chin J Clinicians (Electronic Edition) 2009; 3: 1293-1298, http://www.clinicmed.cn/upload/pdf/200909/ 20090904042355372.pdf.

7. Gautam S, Banerjee M. The macrophage Ox-LDL receptor, CD36 and its association with type II diabetes mellitus. $\mathrm{Mol}$ Genet Metab 2011; 102: 389-398, doi: 10.1016/j.ymgme. 2010.12.012.

8. Rac ME, Safranow K, Rac M, Kurzawski G, Krzystolik A, Sagasz-Tysiewicz D, et al. CD36 gene is associated with thickness of atheromatous plaque and ankle-brachial index in patients with early coronary artery disease. Kardiol Pol 2012; 70: 918-923.

9. Rac M, Safranow K, Kurzawski G, Krzystolik A, Chlubek D. Is CD36 gene polymorphism in region encoding lipid-binding domain associated with early onset CAD? Gene 2013; 530: 134-137, doi: 10.1016/j.gene.2013.06.061.

10. Banerjee M, Gautam S, Saxena M, et al. Association of CD36 gene variants rs1761667(G>A) and $r$ 1527483(C $>$ T) with Type 2 diabetes in North Indian population. Int $\mathrm{J}$ Diabetes Mellit 2010; 2: 179-183, doi: 10.1016/j.ijdm.2010.08.002.

11. Noel SE, Lai CQ, Mattei J, Parnell LD, Ordovas JM, Tucker $\mathrm{KL}$. Variants of the CD36 gene and metabolic syndrome in Boston Puerto Rican adults. Atherosclerosis 2010; 211: 210-215, doi: 10.1016/j.atherosclerosis.2010.02.009.

12. Ma X, Bacci S, Mlynarski W, Gottardo L, Soccio T, Menzaghi C, et al. A common haplotype at the CD36 locus is associated with high free fatty acid levels and increased cardiovascular risk in Caucasians. Hum Mol Genet 2004; 13: 2197-2205, doi: 10.1093/hmg/ddh233.

13. Honda $\mathrm{S}$, Bessho $\mathrm{H}$, Kondo $\mathrm{N}$, Kusuhara $\mathrm{S}$, Tsukahara $\mathrm{Y}$, Negi A. Positive association of CD36 gene variants with the visual outcome of photodynamic therapy in polypoidal choroidal vasculopathy. Mol Vis 2012; 18: 2796-2804.

14. Ministry of Health CDPRC. Prevention of cardiovascular diseases in China report 2011. Beijing: Encyclopedia of China Publishing House; 2012.

15. Pu J, Yuan A, Shan P, Gao E, Wang X, Wang Y, et al. Cardiomyocyte-expressed farnesoid-X-receptor is a novel apoptosis mediator and contributes to myocardial ischaemia/reperfusion injury. Eur Heart J 2013; 34:1834-1845, doi: 10.1093/eurheartj/ehs011.

16. Teupser D, Mueller MA, Koglin J, Wilfert W, Ernst J, von Scheidt W, et al. CD36 mRNA expression is increased in CD14 + monocytes of patients with coronary heart disease. Clin Exp Pharmacol Physiol 2008; 35: 552-556, doi: 10.1111/j.1440-1681.2007.04836.x.

17. Maiwald S, Zwetsloot PP, Sivapalaratnam S, Dallinga-Thie GM. Monocyte gene expression and coronary artery disease. Curr Opin Clin Nutr Metab Care 2013; 16: 411-417.

18. Keller KL, Liang LC, Sakimura J, May D, van Belle C, Breen C, et al. Common variants in the CD36 gene are associated with oral fat perception, fat preferences, and obesity in African Americans. Obesity 2012; 20: 1066-1073, doi: 10.1038/oby. 2011.374.

19. Love-Gregory L, Sherva R, Sun L, Wasson J, Schappe T, Doria A, et al. Variants in the CD36 gene associate with the metabolic syndrome and high-density lipoprotein cholesterol. Hum Mol Genet 2008; 17: 1695-1704, doi: 10.1093/ $\mathrm{hmg} / \mathrm{ddn} 060$.

20. Rac ME, Suchy J, Kurzawski G, Kurlapska A, Safranow K, Rac $M$, et al. Polymorphism of the CD36 gene and cardiovascular risk factors in patients with coronary artery disease manifested at a young age. Biochem Genet 2012; 50: 103-111, doi: 10.1007/s10528-011-9475-z.

21. Koenig W, Karakas M, Zierer A, Herder C, Baumert J, Meisinger $C$, et al. Oxidized LDL and the risk of coronary heart disease: results from the MONICA/KORA Augsburg Study. Clin Chem 2011; 57: 1196-1200, doi: 10.1373/clinchem.2011. 165134.

22. Kuriki K, Hamajima N, Chiba H, Kanemitsu Y, Hirai T, Kato $\mathrm{T}$, et al. Relation of the CD36 gene A52C polymorphism to the risk of colorectal cancer among Japanese, with reference to with the aldehyde dehydrogenase 2 gene Glu487Lys polymorphism and drinking habit. Asian Pac J Cancer Prev 2005; 6: 62-68. 